Original Research Paper

\title{
Dynamic Simulation and Optimum Operation Strategy of a Trigeneration System Serving a Hospital
}

\author{
Francesco Calise, Massimo Dentice d'Accadia, Luigi Libertini, Edoardo Quiriti and Maria Vicidomini \\ Department of Industrial Engineering, University of Naples Federico II, P.le Tecchio,80-80125 Naples, Italy
}

\section{Article history}

Received: 01-08-2016

Revised: 08-08-2016

Accepted: 27-08-2016

Corresponding Author:

Francesco Calise

Department of Industrial

Engineering, University of

Naples Federico II, P.le

Tecchio,80-80125 Naples, Italy

Email: frcalise@unina.it

\begin{abstract}
This paper presents a numerical analysis of a trigeneration system in a hospital, aiming at determining the cost-optimal operating strategy as a function of the energy demands to be matched. The system includes: A natural gas fired reciprocating engine, heat exchangers for waste-heat recovery, a single-stage $\mathrm{LiBr}-\mathrm{H}_{2} \mathrm{O}$ Absorption Chiller ( $\left.\mathrm{ACH}\right)$, a cooling tower, pumps, a backup boiler, a backup vapour-compression electric chiller, storage tanks, valves, mixers. For such system, a dynamic simulation model was developed in TRNSYS environment; the model includes detailed algorithms for all the components of the system. A case study was developed, referred to a hospital application, in which a Combined Heat, Cooling and Power (CHCP) system provides electricity, thermal and cooling energy. The electric energy demand was obtained by using real measured data and calibrating hospital literature data, whereas the demand for heating and cooling was estimated by means of a detailed simulation model. A detailed economic analysis was also included in the model, aiming at investigating the optimal control strategy needed to maximize the overall thermo economic performance of the system. To this scope, different control strategies were analysed. The most conventional operating strategy, Thermal Load Tracking mode (TLT), was compared with two alternative strategies: The Maximum Power Thermal Load Tracking mode (MPTLT) and the Electricity Load Tracking mode (ELT). MPTLT is a strategy featured by a thermal load tracking mode, but the engine, differently from TLT one, operates always at maximum power. ELT is a strategy in which the power provided by the engine is always less or equal to the electrical demand. In the paper, the results of the case study are presented on different time bases (days, weeks, years). Such results show that the ELT control strategy can achieve a better profitability, with a simple pay-back period, SPB, equal to 4 years. The conventional strategy (TLT) is shown to be the worst from the economic point of view, but among the best as for energy saving potential.
\end{abstract}

Keywords: CHCP, Dynamic Simulation, Optimal Management, TRNSYS

\section{Introduction}

Combined Heat, Cooling and Power $(\mathrm{CHCP})$ is a mature and well-known technology used in order to achieve significant energy and economic savings.

In particular, CHCP systems simultaneously produce electricity, heating and cooling using a single energy input (e.g.,: Natural gas).

During the past decades dozens of scientific papers were published, investigating different aspects of CHPC systems. However, several additional research topics are still open, mainly regarding the management and the optimal control of such systems, in the framework of energy markets where prices dramatically vary hour by hour and the management of eventual excess electricity is becoming a critical issue.

Recently, several literature studies based on dynamic simulation of CHCP plants were carried out in order to: (i) accurately assess the performance of CHCP systems; (ii) optimize the design procedure; (iii) simulating possible energy efficiency actions. Such studies analyse the different operation strategies of trigeneration or cogeneration systems (Chicco and Mancarella, 2005; 2006; Sanaye et al., 2008), i.e.,: Operation at rated 
power (base-load operation), thermal-load following or electrical load-following strategies, or hybrid strategies able to match both thermal and electrical demands. As an example, some works regarding the optimizing procedure and the analysis of operation strategies are briefly summarized in the following. Nayak and Radermacher (2004) modelled and simulated a combined cycle cogeneration plant which provides heating, cooling and electricity to the University of Maryland campus. The system consists of two gas turbines with a maximum electrical capacity of $22 \mathrm{MW}$ and a backpressure steam turbine to supply steam to the campus, generating an additional power of 5.5 MW. Detailed results of the thermal/electrical energy and cost savings obtained by employing these technologies were discussed in this study. Espirito Santo (2012) carried out a dynamic simulation of a $425 \mathrm{kWe}$ trigeneration system based on internal combustion engine powered by natural gas and a $355.2 \mathrm{~kW}$ single-effect Absorption CHiller $(\mathrm{ACH})$. The software COGMCI was used to simulate the system. A Brazilian University Hospital was chosen as a case study and two control strategies were compared: The electricity-tracking and the full-load mode. A model for simulation of combined cycle cogeneration plants fuelled by natural gas was developed by Zheng and Furimsky (2003), using ASPEN PLUS. In the case study, the waste heat is used to generate steam and hot water, in a hospital application. The simulation results are in good agreement with the operating data of commercial plant; about 43.6 MW of electricity were generated by the gas turbine, $28.6 \mathrm{MW}$ by the steam turbine. Moussawi et al. (2015) presented a simulation study of trigeneration systems based on diesel engines, used to provide a typical residential family house in Beirut with electrical energy, space heating and cooling and Sanitary Hot Water (SHW); the software TRNSYS was used. Waste heat is recovered using shell-and-tube heat exchangers and thermal storage tank; an ACH was included, with a cooling capacity of $7500 \mathrm{~W}$ and a design COP of 0.7. The results show that SHW thermal energy can be fully supplied all over the year. In addition, by using the optimal storage tanks, up to 52 and $86 \%$ of the space cooling and heating loads can be matched, respectively. Beihong and Weiding (2006) developed an optimal planning method for determining the size of cogeneration plants in consideration of operational strategies, through mixed-integer nonlinear programming. The optimization problem was formulated for a hospital in Shanghai, referred to a gasturbine system. Thermal-following and electricitytracking strategies were taken into account. Piacentino et al. (2015) used an optimization tool to define the layout, design and operation of trigeneration plant for a case study in the hotel sector located in Rome. Different system layout were analysed, two of them based on reciprocating engines and single or double-effect ACHs, while the third including a gas turbine. Two further sensitivity analyses were performed, focused on tax exemption for the fuel consumed in "high efficiency cogeneration mode" and on the dynamic behaviour of the system. A method of designing a trigeneration plant for the case study of a hospital building was presented in (Kavvadias et al., 2010). In this study, a new operation strategy, called "electrical equivalent load following" was proposed: The required electricity is the electricity needed to cover the electric demand and the cooling demand that is not covered by the ACH. The results showed that the new strategy is better than the conventional ones from both economic and energy points of view, when applied with maximum demand tariffs, having two major benefits: Better load matching and peak reduction. Mago and Chamra (2009) studied and optimized the thermal-load following and the electricity-tracking operation strategy and a hybrid electrical-thermal load following strategy of a CHCP system in Columbus (USA). An office building simulated by the software EnergyPlus was considered. For the evaluated city, results show an optimum primary energy consumption and cost reduction equal to 7.5 and $4.4 \%$, respectively, by thermal-following strategy, while the optimum carbon dioxide emissions reduction is $14.8 \%$ for the thermal-load following mode; the hybrid strategy gives good reduction from both energy and economic points of view.

The reported literature review shows that the control strategy of CHP and CHCP systems is a crucial aspect for achieving a suitable system operation and therefore a good economic profitability. Nonetheless, only few papers in literature investigated detailed control strategies based on dynamic simulation models, also considering temperature fluctuations for the components included in the whole CHCP system.

Similarly, only few works addressed the effect of varying set point temperatures and the related control strategies on the overall energy and economic performance of the system. In fact, an optimized control strategy allows all components to adequately operate close to their rated performance (Calise, 2016).

In order to cover such lacks in the literature, the aim of the present study is to develop a dynamic simulation model of a CHCP system, referred to a real Italian hospital, located in Northern Italy. Several simulations were carried out by comparing the TLT strategy, or rather a thermal load tracking mode in which the engine partializes to follow the thermal request, the MPTLT strategy, or rather a thermal load tracking mode in which the engine does not partialize and so it works always at maximum power and the ELT strategy, or rather an electric load tracking mode in which the engine partializes to follow the electrical request, in order to find optimal control strategy, meanwhile maximizing the overall thermo economic performance. 


\section{Layout}

The system layout is shown in Fig. 1. In particular, it consists of a gas-fired reciprocating engine producing electricity and thermal energy. The electricity is mainly used for the hospital equipment and lighting. The thermal energy is used for space heating, space cooling, by a single-stage $\mathrm{LiBr}-\mathrm{H}_{2} \mathrm{O}$ ACH and for SHW production. The main loops modelled (exhaust gases, hot water, chilled water, sanitary hot water, heating and cooling water) are depicted in Fig. 1. The thermal energy is obtained from the engine cooling water and from the exhaust hot gases. To this scope, two heat exchangers are included: The Exhaust gases-Jacket water ExJ, modelled as a shell-and-tube heat exchanger and the Jacket water/heating Water JW, modelled as a plate-fin heat exchanger. ExJ heats the hot water coming from the engine jackets up to the set point temperature, $T_{o u t, J w, E x J}$ (Table 1). JW heats the water of the Heating water loop, stored into the hot stratified storage tank (TKH).
The heating water coming from the top of TKH enters in the backup boiler and then is diverted by D2 to the absorption chiller ACH in summer and to the crossflow Heat Exchanger Winter (HEW) in the winter, using the pumps P5 and P6, respectively.

Thanks to the implemented controls, pump P6 is activated only when heating energy is demanded, the engine in on and the hot water entering in the HEW is higher than $70^{\circ} \mathrm{C}$. Pump P5, ACH and P3, instead, are activated only when cooling energy is demanded, the engine in on and the hot water entering in the absorption chiller is higher than $70^{\circ} \mathrm{C}$.

The ACH produces chilled water CHW that enters, through P3, in the backup electric chiller and then it is stored into a cold stratified storage tank at variable inlets TKC. CHW, from the bottom of TKC is supplied to fan coils systems for the space cooling of building.

The cooling tower CT provides the cooling water required to cool the $\mathrm{ACH}$, by means of $\mathrm{P} 4$. HEW heats the water of fan coils hot water loop, directed to fan coils systems for the space heating of building.

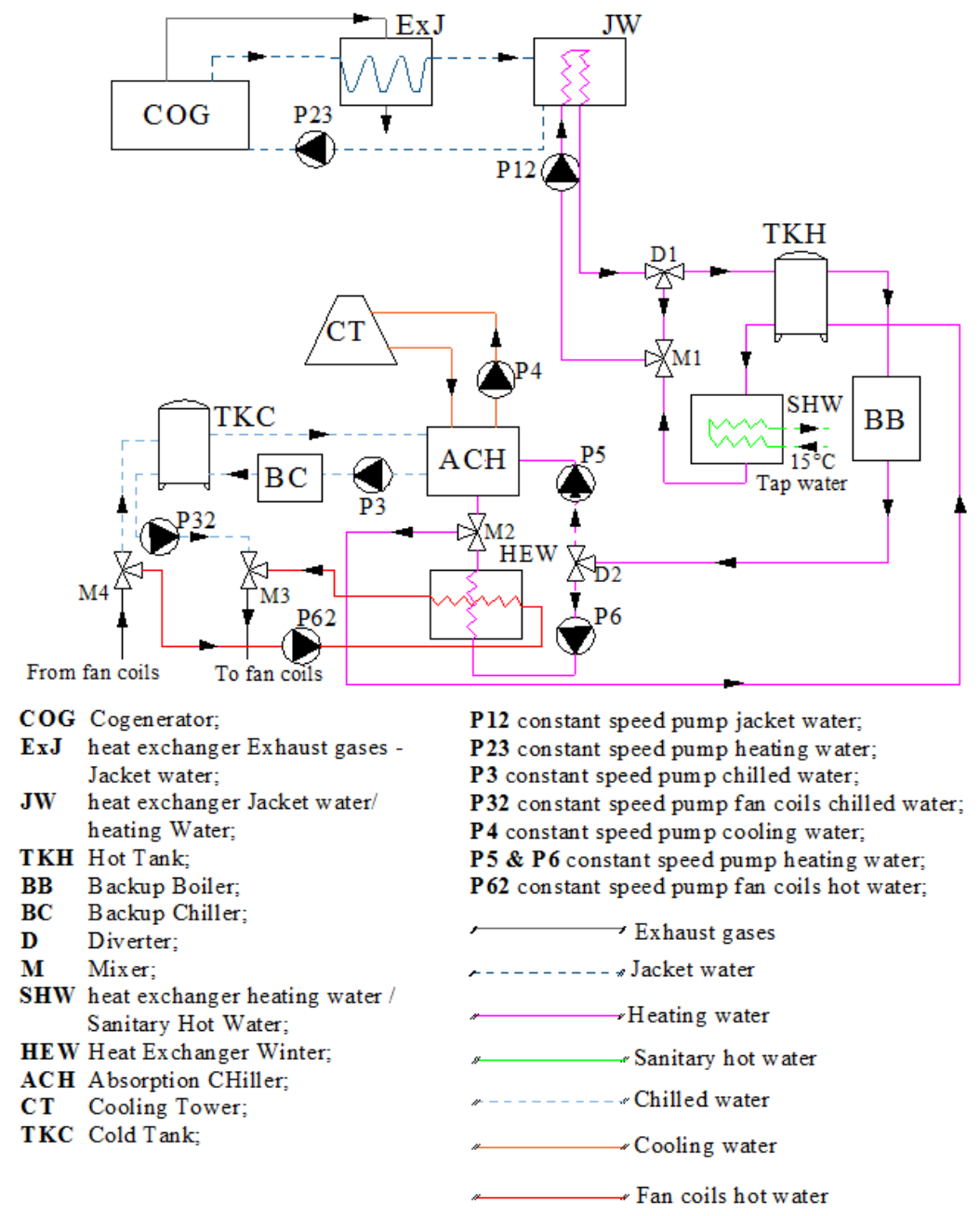

Fig. 1. System layout 
Table 1. Main design parameters (1)

\begin{tabular}{|c|c|c|c|}
\hline Component & Parameter & Value & Unit \\
\hline \multirow[t]{2}{*}{ Cogenerator } & $Q_{\text {th,rated,COG }}$ Thermal rated power & 207 & $\mathrm{~kW}$ \\
\hline & $P_{e l, \text { rated,cog }}$ Electrical rated power & 140 & \\
\hline \multirow[t]{3}{*}{ Heat exchanger exhaust Gases-Jacket water } & $T_{\text {out,ExJ,rated }}$ Jacket water outlet rated temperature & $88-92$ & ${ }^{\circ} \mathrm{C}$ \\
\hline & Exhaust Gases flow rate & 520 & $\mathrm{~kg} / \mathrm{h}$ \\
\hline & Jacket water flow rate (pump P23) & 17780 & \\
\hline \multirow[t]{2}{*}{ Heat exchanger jacket water/heating water } & $T_{\text {in, set, } J W} \mathrm{JW}$ inlet set point temperature & 70 & ${ }^{\circ} \mathrm{C}$ \\
\hline & Heating Water flow rate (pump P12) & 8903 & $\mathrm{~kg} / \mathrm{h}$ \\
\hline \multirow{2}{*}{ Heat exchanger heating water/sanitary hot water } & Heating Water flow rate (pump P12) & 8903 & \\
\hline & Sanitary hot water flow rate (average) & 1333 & \\
\hline
\end{tabular}

Table 2. Main design parameters (2)

\begin{tabular}{|c|c|c|c|}
\hline Component & Parameter & Value & Unit \\
\hline \multirow[t]{4}{*}{ Heat exchanger winter } & Heating water flow rate (pump P6) & 17200 & $\mathrm{~kg} / \mathrm{h}$ \\
\hline & Fan coils hot water flow rate (pump P62) & 71428 & \\
\hline & $\Delta T_{H E}$ Tolerance on HEW activation temperature & 2 & ${ }^{\circ} \mathrm{C}$ \\
\hline & $T_{\text {set, } H E W}$ Set point temperature for space heating activation & 70 & \\
\hline \multirow[t]{7}{*}{ Chiller } & Chilled water set point temperature & 7 & \\
\hline & $\mathrm{T}_{\text {set, } A C H}$ Set point temperature for space cooling activation & 75 & \\
\hline & $\Delta T_{A C H}$ Tolerance on $\mathrm{ACH}$ activation temperature & 5 & \\
\hline & Hot water flow rate (pump P5) & 32400 & $\mathrm{~kg} / \mathrm{h}$ \\
\hline & Chilled water flow rate (pump P3) & 27500 & \\
\hline & Fan coils chilled water flow rate (pump P32) & 59143 & \\
\hline & Rated cooling capacity & 175.8 & $\mathrm{~kW}$ \\
\hline \multirow[t]{3}{*}{ Cooling tower } & Cooling water flow rate (pump P4) & 91800 & $\mathrm{~kg} / \mathrm{h}$ \\
\hline & Air flow rate & 33480 & \\
\hline & Rated cooling capacity & 425 & $\mathrm{~kW}$ \\
\hline Cold tank & Volume & 3 & $\mathrm{~m}^{3}$ \\
\hline Hot tank & & 6 & \\
\hline \multirow[t]{5}{*}{ Fan coils } & Rated heating and cooling capacity for floors zone & $280 / 271$ & $\mathrm{~kW}$ \\
\hline & Rated heating and cooling capacity for basement zone & $146 / 85$ & \\
\hline & Rated heating and cooling capacity for attic zone & $105 / 110$ & \\
\hline & Rated heating and cooling capacity for operating rooms zone & $103 / 86$ & \\
\hline & $T_{\text {set,chw }, F C}$ Set point inlet chilled water temperature & 15 & ${ }^{\circ} \mathrm{C}$ \\
\hline
\end{tabular}

Thermal energy of COG is also used by the heat exchanger heating Water/Sanitary Hot Water, SHW to produce SHW. With regard to $\mathrm{ACH}$, cooling tower and HEW, other controllers were included in order to achieve the desired value of temperatures, $T_{\text {set, } A C H}$ and $T_{\text {set, } H E W}$ for their activation (Table 2). In particular, ACH and HEW are controlled by an ON/OFF hysteresis controller which monitors the TKH top temperatures and shuts down the $\mathrm{ACH}$ and HEW (by switching off P6 and P62) when such value falls down the set point value, in order to prevent both systems from operating at low capacity and efficiency. The ACH and HEW are re-activated when the temperature overcomes the same set-point temperatures, increased of a dead band $\Delta T_{A C H}$, required to reduce the number of start-up and shut-down events. In order to control the temperature of the chilled water entering the fan coils (set point $T_{\text {set,chw,FC}}$ ) and simultaneously the cooling energy demand of the building, the pump P32 is managed by an ON/OFF hysteresis controller which monitors the TKC bottom temperatures, $T_{\text {TНС,ВОттом }}$.

Such controller prevents from supplying high temperature water to the fan coils. Regarding the COG operation strategy, it is assumed that COG "follows" the thermal load. In particular, another ON/OFF hysteresis controller lets the COG switch off when the water temperature coming from the SHW is higher than $72^{\circ} \mathrm{C}$ and lets the COG activate when the same temperature is lower than $67,5^{\circ} \mathrm{C}$. A feedback controller, instead, attends when this temperature is too low, bypassing a part of the heating water flow rate entering in the TKH; in this way, all the values of the cogenerator data sheet are complied with. At last, a proportional control makes the COG operate at part-load, as a function of the temperature of the water coming from the SHW, from 50 to $100 \%$ of the maximum power.

The backup boiler is activated only when the following conditions are verified: The cogenerator is on and works in full-load conditions, the heating demand is high, the temperature of the water coming from the SHW is between 64 and $70^{\circ} \mathrm{C}$, the external air temperature is lower than $10^{\circ} \mathrm{C}$ and the inlet temperature is lower than $85^{\circ} \mathrm{C}$. The boiler is able to modulate the outlet water temperature (from 83 to $87^{\circ} \mathrm{C}$ ) in function of the external air temperature. The backup electrical chiller, instead, is 
activated (thanks to an ON/OFF hysteresis controller) when the temperature of the $\mathrm{CHW}$ produced by the $\mathrm{ACH}$ is higher than $10^{\circ} \mathrm{C}$.

\section{Simulation Model}

The performance of the system was simulated by means of TRNSYS 17. Such software, diffusely adopted by the academic community, allows one to perform transient energy simulations, based on a library of builtin components (e.g., pumps, mixers, diverters, valves, controllers, heat exchangers, etc.), often based on experimental data (Klein, 2006).

This section provides a brief description of the mathematical models of the main components-called "types" in TRNSYS-included in the system layout. In particular, for sake of brevity, such discussion is limited to the absorption chiller and to the internal combustion engine. The remaining models (controllers, psychometrics routine, pipes connecting, schedulers, heat exchangers, cooling tower etc.) are widely discussed in reference (Klein, 2006).

In order to calculate the heating and cooling load of the building simulated, the Google Sketch UP tool for designing 3D buildings was used. In particular, the building model was firstly implemented by such tool and subsequently imported in TRNSYS by using the TRNSYS3d plug-in (Aschaber et al., 2009).

The design parameters of the CHCP plant and the assumptions regarding the building are shown in Table 1, 2, 4 and 5 .

\section{Absorption Chiller}

A single-effect $\mathrm{LiBr}-\mathrm{H}_{2} \mathrm{O}$ ACH was considered. The component is simulated using a normalized catalogue data look-up approach (ASHRAE, 2001), according to the TRNSYS Type 107 model. The ACH nominal capacity is calculated as:

$$
\dot{Q}_{c, A C H, \text { rated }}=f_{A C H} \dot{m} c_{p} \Delta T_{C H W, n}
$$

The performance data are numerically expressed by the cooling ratio factor and the input heat ratio factor, respectively, as shown in Equation 2 and 3:

$$
\begin{gathered}
f_{Q_{C}}=\frac{\dot{Q}_{c, A C H}}{\dot{Q}_{c, A C H, \text { rated }}}=\vartheta\left(T_{\text {SETout }, C H W}, T_{i n, \mathrm{CW}}, T_{i n, H W}, T_{i n, C H W}, f_{D L}\right) \\
f_{Q_{H}}=\frac{\dot{Q}_{H, A C H}}{\dot{Q}_{H, A C H, \text { rated }}}=\vartheta\left(T_{\text {SETout }, \mathrm{CHW}}, T_{\text {in }, \mathrm{CW}}, T_{\text {in }, H W}, T_{\text {in }, \mathrm{CHW}}, f_{D L}\right)
\end{gathered}
$$

Note that the rated input $\mathrm{HW}$ rate $\dot{Q}_{H, A C H \text {,rated }}$ is determined in relation to a fixed value of the coefficient of performance of the $\mathrm{ACH}$ :
$\dot{Q}_{H, A C H, \text { rated }}=\frac{\dot{Q}_{c, A C H, \text { rated }}}{C O P_{A C H, \text { rated }}}$

The thermal rate required to cool the $\mathrm{ACH}$ is:

$\dot{Q}_{A C H, \mathrm{c}, \text { req }}=\dot{m}_{C H W} c_{p, C H W}\left(T_{i n, C H W}-T_{\text {setout }, \text { CHW }}\right)$

Therefore, the design load ratio is:

$f_{D L}=\frac{\dot{Q}_{A C H, c, r e q}}{\dot{Q}_{A C H, c, \text { rated }}}$

Thus, the cooling and heating rate at any given time can be computed by the factors defined in Equation 2 and 3.

Such values are subsequently employed in the energy balances, in order to calculate the outlet temperatures for $\mathrm{HW}, \mathrm{CHW}$ and $\mathrm{CW}$.

\section{Internal Combustion Engine}

The model of the CHCP system is based on the Type 907 included in TRNSYS library (Klein, 2006). This model simulates the performance of the engine as a function of: Air intake temperature, jacket fluid temperature and flow rate, oil cooler fluid temperature and flow rate, after cooler cooling fluid temperature and flow rate. In particular, the model provides: Electrical energy, exhaust gas temperature and flow rate, jacket fluid outlet temperature and flow rate, oil cooler fluid outlet temperature and flow rate, after cooler cooling fluid outlet temperature and flow rate, as a function of the above mentioned input parameters. The model is based on simple energy and mass balances and on a data look-up approach: The performance of the engine is calculated on the basis of a map numerically provided by the user. In the following, the main equations of engine model are reported.

The engine partial load ratio is defined in Equation 7 and depends on the electrical load, $P_{r e q}$ and on the CHCP rated power, $P_{\text {el, rated, } C H C P}$ :

$$
P L R=\min \left(1, \frac{P_{\text {req }}}{P_{\text {el, rated }, C H C P}}\right)
$$

The mechanical and electrical efficiency are calculated as:

$\eta_{m}=\frac{P_{\text {shaft }}}{\dot{Q}_{\text {fuel }}} \eta_{e l}=\frac{P_{\text {el, rated }, \text { CHCP }} P L R}{P_{\text {shaft }}}$

Through a thermal balance, the temperature of the jacket water leaving the engine $(J)$ is evaluated by considering the fraction of thermal energy recovered, $F$ : 


$$
T_{J \text { out }}=T_{J \text { in }}+\frac{F_{J}\left(\dot{Q}_{\text {required }}-P_{\text {shaft }}\right)}{\dot{m}_{J} c_{p, J}}
$$

Finally, the temperature of the cooling water at the outlet of the engine oil (OC) and After Cooler (AC) heat exchangers and the temperature of the exhaust gases (exh) are calculated, Equation 10-12:

$$
\begin{aligned}
& T_{O C \text { out }}=T_{O C \text { in }}+\frac{F_{O C}\left(\dot{Q}_{\text {fuel }}-P_{\text {shaft }}\right)}{\dot{m}_{O C} c_{p, O C}} \\
& T_{A C \text { out }}=T_{A C \text { in }}+\frac{F_{A C}\left(\dot{Q}_{\text {fuel }}-P_{\text {shaft }}\right)}{\dot{m}_{A C} c_{p, A C}} \\
& T_{\text {exh out }}=T_{\text {intake }}+\frac{F_{\text {exh }}\left(\dot{Q}_{\text {fuel }}-P_{\text {shaft }}\right)}{F_{\text {exh flow }} \dot{m}_{\text {rated }, \text { exh }} c_{p, \text { exh }}}
\end{aligned}
$$

\section{Energy and Economic Evaluation}

A detailed thermo-economic model was developed in order to assess the energy and economic profitability of the system under investigation. Such model takes into account the current Italian legislation (Calise et al., 2012), based on the European Directory 2004/8/CE.

In order to evaluate a CHCP plant as a High Efficiency Cogeneration (HEC) unit, several indexes are defined: The primary energy saving PES-Equation 13, the global efficiency $\eta_{g l o b}$-Equation 14 and the effective coefficient $C_{\text {eff }}$-Equation 15 . In the case under evaluation, a $P E S_{\min }$ equal to 0 is required, because the rated electrical power of the cogeneration unit is below 1 MW (Calise et al., 2009):

$$
P E S=1-\frac{E_{\text {fuel }}}{\frac{E_{e l, c o g}}{\eta_{e l, r e f}}+\frac{E_{\text {th }, \text { cog, useful }}}{\eta_{\text {th }, \text { ref }}}} \geq P E S_{\text {min }}
$$

$\eta_{\text {el,ref }}$ and $\eta_{\text {th,ref }}$ are the reference efficiencies for the separate production of electricity and thermal energy, respectively.

$\eta_{g l o b}$ is calculated as:

$$
\eta_{g l o b}=\frac{E_{e l, c o g}+E_{t h, c o g, u s e f u l}}{E_{f u e l}}
$$

where, $E_{e l, c o g}$ and $E_{t h, c o g, u s e f u l}$ are the yearly electricity and useful thermal energy produced by the system, respectively and $E_{f u e l}$ is the corresponding primary energy input.

The coefficient $C_{\text {eff }}$ quantifies the amount of the electricity production, $E_{e l, c o g}$ which can be formally considered as produced in cogeneration mode, $E_{\text {el,cogenerated }}$ and is calculated by assuming that $\eta_{g l o b}$ is equal to the minimum global efficiency $\eta_{g l o b, \min }$ defined by the law $(75 \%$, for reciprocating engines). Such coefficient is calculated by Equation 15:

$$
C_{e f f}=\frac{E_{e l, c o g e n e r a t e d}}{E_{t h, c o g, u s e f u l}}=\frac{\eta_{e l, c o g}}{\eta_{g l o b, \text { min }}-\eta_{e l, c o g}}
$$

where, $\eta_{e l, c o g}$ is the electrical efficiency of cogenerator and $\eta_{\text {glob, min }}$ is equal to 0.75 .

In case is $\eta_{g l o b} \geq 0.75, E_{\text {el,cogenerated }}$ is assumed equal to $E_{\text {el,cog. }}$.

The HEC units can benefit of an incentive proportional to the primary energy saving acknowledged, equal roughly to $100 € /$ toe, also known as Energy Savings Certificates (ESC). In this case, the overall economic saving of the CHCP system is evaluated as:

$$
\begin{aligned}
& A C=0.086 \cdot k \cdot\left(\frac{E_{e l, \text { cogenerated }}}{\eta_{e l, R S}}+\frac{E_{\text {th, cog, useful }}}{\eta_{t h, R S}}-E_{\text {fuel }}\right) E S C+ \\
& +\left(\frac{E_{c h, A C H}}{C O P_{R S, H P}}+E_{e l, \text { cogenerated }}\right) \cdot c_{e l, R S}+ \\
& \frac{E_{t h, H E W}+E_{t h, D H W}}{\eta_{t h, R S, b o i l e r} L C V_{N G}} \cdot c_{G N, R S}-M-C_{e l, s y s t e m}-C_{f u e l}-C_{f e s s, e l}
\end{aligned}
$$

Where:

$k=\mathrm{A}$ coefficient depending on the power capacity (1.4 in our case)

$M \quad=$ The maintenance cost

$C_{\text {elsystem }}=$ The general charges of the system

$C_{\text {fuel }} \quad=$ The cost due to natural gas consumption

$C_{\text {fees,el }}=$ The fees for the electricity generated and directly consumed by user

$E_{c h, A C H} \quad=$ The chilled energy produced by $\mathrm{ACH}$

$E_{t h, H E W}$ and $E_{t h, S H W}=$ The thermal energy produced by HEW and SHW heat exchangers, respectively.

The equations implemented for calculating the last four terms of the overall economic saving are resumed as follows:

$$
\left\{\begin{array}{l}
M=E_{e l, c o g} \cdot c_{M} \\
C_{e l, s y s t e m}=i \cdot P_{e l, \text { rated }, c o g} \\
C_{\text {fuel }}=V_{G N, \text { taxfree }} \cdot c_{G N, \text { taxfree }}+ \\
+\left(V_{G N, \text { tot }}-V_{G N, \text { taxfree }}\right) \cdot\left(c_{G N, \text { taxfree }}+c_{f e e}\right) \\
C_{\text {fees }, e l}=E_{e l, c o g} \cdot c_{\text {fees }, e l}
\end{array}\right.
$$

In Table 3, all the parameters adopted in Equation 16 and 17 are resumed. 
The economic analysis also includes the assessment of the Simple Pay Back (SPB) period, the Net Present Value (NPV) and the Profit Index (PI):

$$
\begin{aligned}
& S P B=\frac{J_{t o t}}{\Delta C} \\
& N P V=\Delta C \cdot A F-J_{t o t} \\
& P I=\frac{N P V}{J_{t o t}}
\end{aligned}
$$

$I_{\text {tot }}$ represents the total capital cost of the CHCP system and includes the cost of $\mathrm{ACH}$, cooling tower and cogenerator unit. In particular, the components costs were estimated from commercial catalogues and were provided by manufacturers' quotation: $41 € / \mathrm{kW}$ and 398 $€ / \mathrm{kW}$ of cooling capacity for cooling tower and $\mathrm{ACH}$, respectively and $1043 € / \mathrm{kW}$ of rated power capacity for the cogeneration unit. $A F$ is the annuity factor and was calculated assuming a time horizon of 15 years and a discount rate of 0.05 and is equal to 10.38 .

\section{Case Study}

A case study was developed, referred to a hospital application, in which the electric energy provided by the CHCP system is mainly used for the hospital equipment and lighting, whereas the waste heat is used for providing Sanitary Hot Water (SHW), space heating and cooling purposes. The data regarding the electric energy demand of the hospital were measured over a 1-year campaign, as showed in Fig. 2, in which it is possible to note that the electrical load is practically always above the engine maximum electrical power, $P_{e l, \max }$ and always above the engine minimum electrical power, $P_{e l, m i n}$. The CHCP was assumed to run for the whole year. The simulation model and design parameters of the systems were accurately calibrated in order to match the performance data and the features of the real cogeneration system to be installed. The simulations were mainly carried out by taking into account a weather zone of Northern Italy, Forlì, where the hospital is located. In particular, four different thermal zones were created: The Floors Zone, the Basement Zone, the Attic Zone and the Operating Rooms Zone. The $3 \mathrm{D}$ buildings configuration is represented in Fig. 3. The assumptions adopted for the simulation of all the zones are summarized in Table 4 and 5.

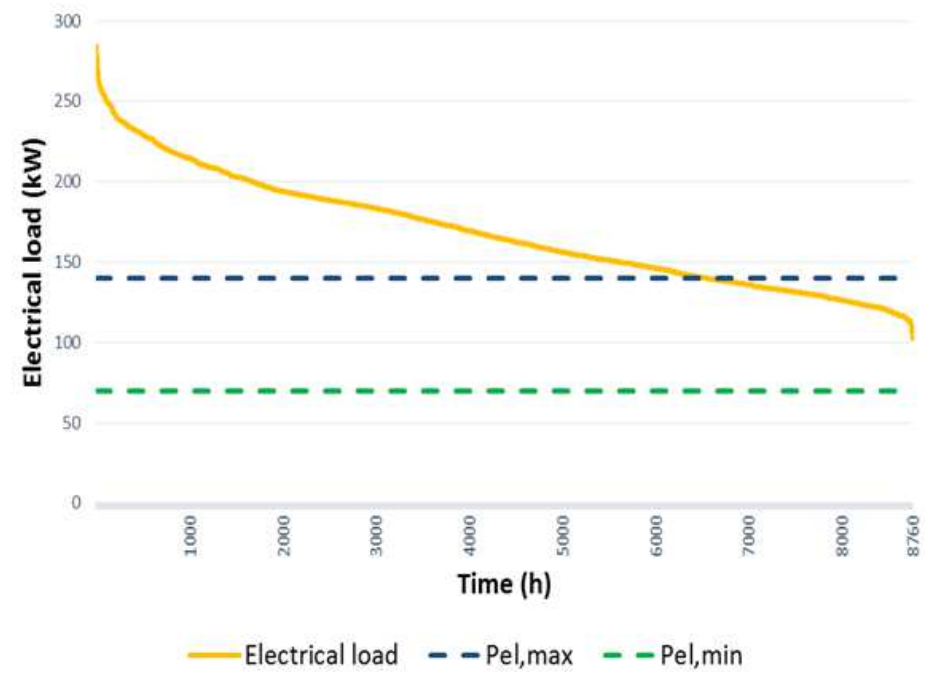

Fig. 2. Electrical load

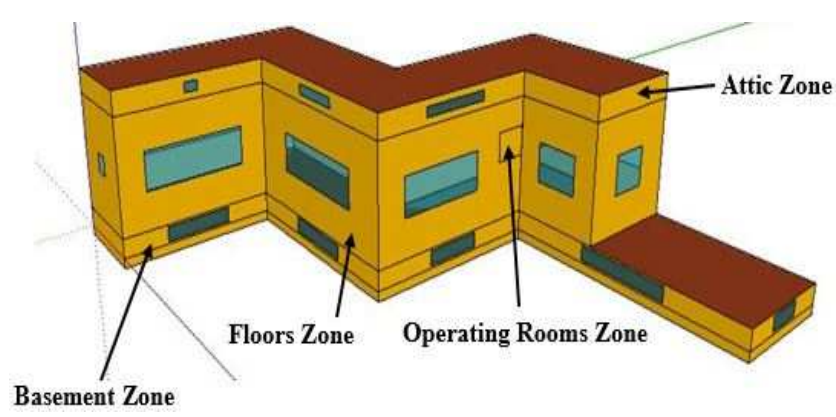

Fig. 3. 3D buildings 
Table 3. Efficiency and economic parameters

\begin{tabular}{|c|c|c|c|}
\hline Parameter & Description & Value & Unit \\
\hline$\eta_{\text {el, ref }}$ & Reference electrical efficiency, PES & 0.46 & - \\
\hline$\eta_{\text {th, ref }}$ & Reference thermal efficiency, PES & 0.9 & \\
\hline$\eta_{\text {th, RS, boiler }}$ & Thermal efficiency of the reference system & 0.85 & \\
\hline$k$ & Coefficient & 1.4 & \\
\hline$C O P_{R S, H P}$ & Coefficient of performance of the reference system (electric chiller) & 3 & \\
\hline$i$ & Unit cost of grid service for CHP systems & 8.19 & $€ / \mathrm{kW}$ \\
\hline$c_{e l, R S}$ & Electricity of reference system (National Grid) & 0.14 & $€ / \mathrm{kWh}$ \\
\hline$c_{e l, \text {, ystem }}$ & General charges on electric energy consumption & 0.016 & \\
\hline$c_{M}$ & Specific maintenance cost & 0.015 & \\
\hline$c_{\text {fees,el }}$ & Fees for self-produced electricity & 0.0125 & \\
\hline$c_{N G, R S}$ & Natural gas cost of reference system (Boiler) & 0.38 & $€ / \mathrm{Sm}^{3}$ \\
\hline$c_{N G, \text { taxfree }}$ & Specific cost of tax free gas consumption & 0.32 & \\
\hline$c_{\operatorname{tax}}$ & Tax on gas consumption & 0.0187 & \\
\hline$L C V$ & Lower calorific value & 9.59 & $\mathrm{kWh} / \mathrm{Sm}^{3}$ \\
\hline
\end{tabular}

Table 4. Assumptions for the simulation of the hospital building

\begin{tabular}{|c|c|c|c|c|}
\hline Thermal zone & Floors & Attic & Basement & Operating rooms \\
\hline \multirow{2}{*}{ Set point indoor air temperature $\left[{ }^{\circ} \mathrm{C}\right]$} & \multicolumn{3}{|c|}{$\mathrm{T}_{\text {setHeat }}: 21 \pm 1$} & $\mathrm{~T}_{\text {setHeat }}: 21$ \\
\hline & \multicolumn{3}{|c|}{$\mathrm{T}_{\text {setCool }}: 26 \pm 1$} & $\mathrm{~T}_{\text {setCool }}: 24$ \\
\hline Occupancy schedule $[\mathrm{h}]$ & 00:00-24:00 & $8: 00-17: 00$ (working days) & 00:00-24:00 & 7:00-21:00 \\
\hline Number of occupants per zone & 400 & 10 & 100 & 15 \\
\hline \multirow{2}{*}{ People heat gain $[\mathrm{W} / \mathrm{p}]$} & Sensible: 90 & Sensible: 165 & Sensible: 100 & Sensible: 100 \\
\hline & Latent: 95 & Latent: 300 & Latent: 130 & Latent: 205 \\
\hline Light heat gains schedule $[\mathrm{h}]$ & 00:00-24:00 & 8:00-17:00 (working days) & 00:00-24:00 & 7:00-21:00 \\
\hline Machineries heat gains schedule $[\mathrm{h}]$ & 00:00-24:00 & 8:00-17:00 (working days) & 00:00-24:00 & $7: 00-21: 00$ \\
\hline Light + machineries heat gains $\left[\mathrm{W} / \mathrm{m}^{2}\right]$ & 10 & 13 & 13 & 100 \\
\hline Air infiltration rate $[\mathrm{vol} / \mathrm{h}]$ & 2 & 1 & 2 & 20 \\
\hline SHW set point temperature $\left[{ }^{\circ} \mathrm{C}\right]$ & & 45 & & \\
\hline Tap water temperature $\left[{ }^{\circ} \mathrm{C}\right]$ & & 14 & & \\
\hline
\end{tabular}

Table 5. Features of the opaque elements (U-values, thicknesses)

\begin{tabular}{llcc}
\hline Zone & Building element & U-value [W/m $\left.{ }^{2} \mathrm{~K}\right]$ & Thickness [m] \\
\hline Attic & Roof & 0.670 & 0.220 \\
& External wall & 0.714 & 0.245 \\
& Adjacent ceiling (Floors) & 1.110 & 0.440 \\
Floors & Windows glass & 2.830 & 0.004 \\
& Adjacent ceiling (Attic) & 1.110 & 0.440 \\
& External wall & 0.714 & 0.245 \\
& Adjacent ceiling (Basement) & 1.110 & 0.440 \\
Windows glass & 2.830 & 0.004 \\
Basement & Adjacent wall (Operating Rooms) & 1.306 & 0.340 \\
& Adjacent ceiling (Floors) & 1.110 & 0.440 \\
& External wall & 0.714 & 0.245 \\
Operating rooms & Ground floor & 0.794 & 0.550 \\
& Windows glass & 2.830 & 0.004 \\
& Adjacent ceiling (Floors) & 1.110 & 0.440 \\
\hline
\end{tabular}

\section{Results}

In the following sections, yearly, weekly and daily results are discussed. For sake of brevity, the majority of the results reported refer to the TLT strategy, in which the engine is controlled in order to match the thermal demand of building; however, some of the results referred to other strategies are discussed, too.

\section{Yearly Results}

The results of the annual simulation are summarized in Table 6 and 7. In Table 6, the TLT strategy is compared with the MPTLT and ELT strategies. The electricity consumption of the auxiliary devices, $E_{e l, a u x}$, is always negligible compared to electricity, $E_{\text {el,cog }}$ and thermal energy, $E_{t h, J W}$. The electrical energy, $E_{e l, c o g}$, the chilled 
energy, $E_{c h, A C H}$ and the thermal energy, $E_{t h, J W}$, produced by the cogenerator are higher in MPTLT strategy and much higher in ELT compared to TLT strategy. However, it is possible to apply the ELT strategy only through a heat dissipation of $490 \mathrm{MWh} /$ year. This circumstance leads to a low ELT global efficiency (0.756) compared to the TLT one (0.899) and MPTLT one (0.903); in any case, such value is sufficient to obtain subsidies (Table 7). In the same table, other important energy and economic indexes are listed, such as the Primary Energy Saving, PES and the Simple Pay-Back, SPB. ELT strategy shows the best economic performance although its PES is not the best one. Economic benefits of all the analyzed strategies are also due to the incentives allowed by the Italian legislation; in fact, a part of the fuel is not subject to taxes ( $V_{N G \text {,taxfee }}$, which is a significant amount of the total fuel consumption) and, more important, Energy Savings Certificates (ESC) are present.

\section{Weekly Results}

The system was also analyzed on a weekly basis, in order to better evaluate the variation of energy flows and system performance during the year. In Fig. 4, the thermal energy flows are reported, related to the jacket water, gasesjacket water, sanitary hot water heat exchangers and boiler ( $E_{t h, J W}, E_{t h, G J}$ and $E_{t h, S H W}, E_{t h, B o i l e r}$, respectively), as well as the electrical production of reciprocating engine, $E_{e l, c o g}$ and the electricity consumption of the auxiliary devices, $E_{\text {el,aux }}$, considering the TLT strategy. It is clearly shown that $E_{e l, a u x}$ is negligible compared to the other terms. The trends of all the parameters show minimum values in summer. This result can be explained considering that the reciprocating engine is following the real thermal demand of the hospital. $E_{t h, S H W}$ is quite constant during the whole year, while the backup boiler produces thermal energy, $E_{t h, \text { Boiler }}$, only in winter, when the thermal request is very high.

Conversely, the results depicted in Fig. 5 show a remarkable seasonal trend. In fact, by observing the cooling energy produced by $\mathrm{ACH} E_{c h, A C H}$ and by the electrical chiller $E_{\text {ch,el.chiller }}$, an increase of the cooling demand can be noted during summer season. In this period, the thermal energy used for heating purpose, $E_{t h, H E W}$, is equal to zero and so the thermal energy request, $E_{t h, r e q}$, is only due to the SHW; for this reason it is possible to use the thermal energy produced by cogenerator to activate the $\mathrm{ACH}$.

Table 6. Yearly energy results

\begin{tabular}{|c|c|c|c|c|}
\hline Strategy & TLT & MPTLT & ELT & \\
\hline$\overline{E_{e l, \operatorname{cog}}}$ & 808 & 869 & 1203 & \multirow{9}{*}{ MWh/year } \\
\hline$E_{e l, a u x}$ & 9 & 9 & 10 & \\
\hline$E_{c h, A C H}$ & 156 & 158 & 184 & \\
\hline$E_{c, A C H}$ & 350 & 361 & 435 & \\
\hline$E_{t h, A C H}$ & 192 & 202 & 250 & \\
\hline$E_{t h, E x J}$ & 479 & 481 & 672 & \\
\hline$E_{t h, J W}$ & 1261 & 1285 & 1794 & \\
\hline$E_{t h, H E W}$ & 995 & 996 & 996 & \\
\hline$E_{t h, S H W}$ & 393 & 459 & 459 & \\
\hline
\end{tabular}

Table 7. Yearly economic and energy results

\begin{tabular}{|c|c|c|c|c|c|}
\hline \multirow[b]{2}{*}{ Description } & \multicolumn{5}{|c|}{ Control strategy } \\
\hline & Name & TLT & MPTLT & ELT & Unit \\
\hline Global efficiency & $\eta_{g l o b}$ & 0.899 & 0.903 & 0.756 & - \\
\hline Operation equivalent hours & $H_{e q}$ & 5768 & 6209 & 8594 & hours \\
\hline Cogenerator required energy & $E_{\text {fuel }}$ & 2301 & 2386 & 3318 & MWh/year \\
\hline Yearly electricity & $E_{\text {el, cog }}$ & 808 & 869 & 1203 & \\
\hline Useful thermal energy & $E_{\text {th, }, \text { useful }}$ & 1250 & 1272 & 1291 & \\
\hline Primary energy saving & $P E S$ & 23 & 24 & 14 & $\%$ \\
\hline Effective coefficient & $C_{e f f}$ & 1 & 1 & 1 & - \\
\hline Total Fuel consumption & $V_{N G, t o t}$ & 279992 & 288011 & 393886 & $\mathrm{Sm}^{3} /$ year \\
\hline Tax free volume fuel consumption & $V_{N G, \text { taxfree }}$ & 177652 & 191245 & 264710 & \\
\hline Energy savings certificates & ESC & 11800 & 12800 & 11300 & $€ /$ year \\
\hline Economic saving for cooling & $S_{\text {Cool }}$ & 7285 & 7344 & 8569 & \\
\hline Economic saving for heating and SHW & $S_{\text {Heat }}+S_{S H W}$ & 64691 & 64995 & 66935 & \\
\hline Economic saving for electricity & $S_{e l}$ & 109821 & 117511 & 166438 & \\
\hline Total economic saving & $S_{\text {tot }}$ & 182480 & 190880 & 241941 & \\
\hline Electrical operating cost & $C_{o p, e l}$ & 10094 & 10886 & 15040 & \\
\hline Fuel cost & $C_{\text {fuel }}$ & 91511 & 93973 & 128459 & \\
\hline System cost & $C_{e l, s y s t e m}$ & 1147 & 1147 & 1147 & \\
\hline Maintenance cost & $M$ & 12113 & 14343 & 18048 & \\
\hline Total cost & $C_{\text {tot }}$ & 104770 & 109463 & 147654 & \\
\hline
\end{tabular}




\section{Daily Dynamic Results}

In this section, the hourly results of the simulations are discussed. For a representative winter day, March 8th, the operating temperatures of the heat exchanger JW are reported in Fig. 6. It is possible to note that, thanks to engine map calibration, the heating water increases its temperature from $70^{\circ} \mathrm{C}\left(T_{i n, J W}\right)$ to $90^{\circ} \mathrm{C}\left(T_{\text {out JWW }}\right)$ while the hot source water decreases its temperature from $92^{\circ} \mathrm{C}$ $\left(T_{i n, h o t}\right)$ to $82^{\circ} \mathrm{C}\left(T_{\text {out hot }}\right)$, following design values. Such result is also due to the detailed calibration of all the model to the specific engine under investigation, with special reference to the parameters of the heat exchangers (number of shell passes, overall heat transfer coefficient in the heat exchangers, heat exchanger effectiveness, etc.).

Through daily dynamic results, it is also possible to verify the implemented controls. For example, in Fig. 7, the cogenerator controls are reported for a representative winter day, March $23^{\text {rd }}$, still considering the TLT strategy. The engine reduces its power output as a function of the outlet water temperature from the SHW, $T_{\text {out }, S H W}$ : When this temperature is lower than $65^{\circ} \mathrm{C}$, the engine works at maximum power, instead, when it is higher than $72^{\circ} \mathrm{C}$, the engine turns off and, lastly, when the temperature goes from 65 to $72^{\circ} \mathrm{C}$, the engine operates in part-load conditions. In this way, the temperature at the inlet of the engine, $T_{\text {ret, cog, }}$, is stably $70^{\circ} \mathrm{C}$.

It is also important to check if the set point indoor air temperatures are respected. For this reason, in Fig. 8, the Floors Zone indoor air temperature, $T_{\text {int,air }}$, is reported for a representative winter day, January 15 th. It is noticeable that this temperature is very close to the set point one $\left(21 \pm 1^{\circ} \mathrm{C}\right)$ and this happens for the whole years and for all the thermal Zones.

In the MPTLT strategy, the engine works always at maximum power and so, in this way, the energetic production is higher. In fact, thanks to this strategy, the operation equivalent hours pass from 5768 (TLT strategy) to 6209 . However, working at maximum power, the engine turns off several times than the previous strategy, passing from 4700 to 5528 times off, causing an increase in maintenance costs even if this strategy presents better economic benefits. For example, in Fig. 9, it is possible to note the greater number of off in the MPTLT strategy for a representative day, November 18 th.

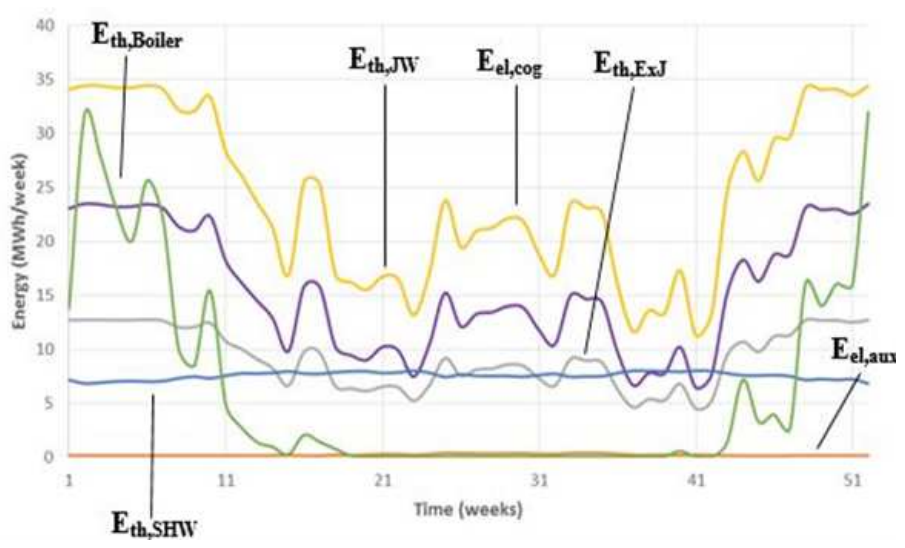

Fig. 4. Weekly energy (1)

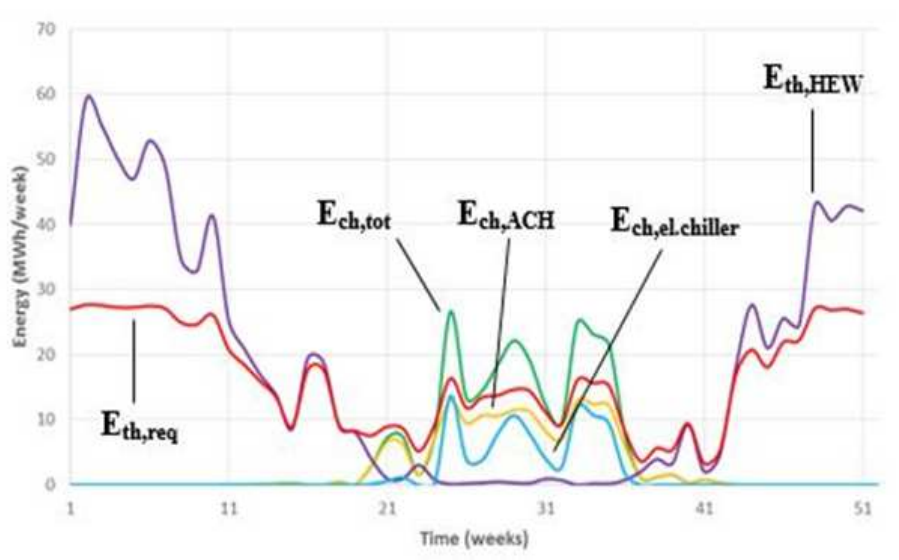

Fig. 5. Weekly energy (2) 


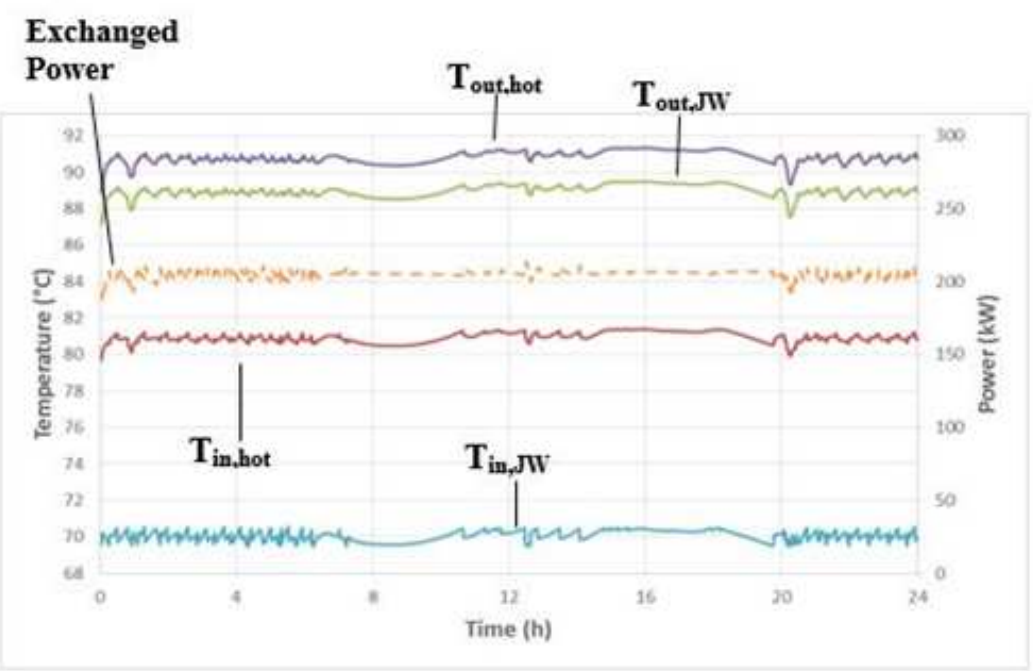

Fig. 6. Heat exchanger JW operating temperatures

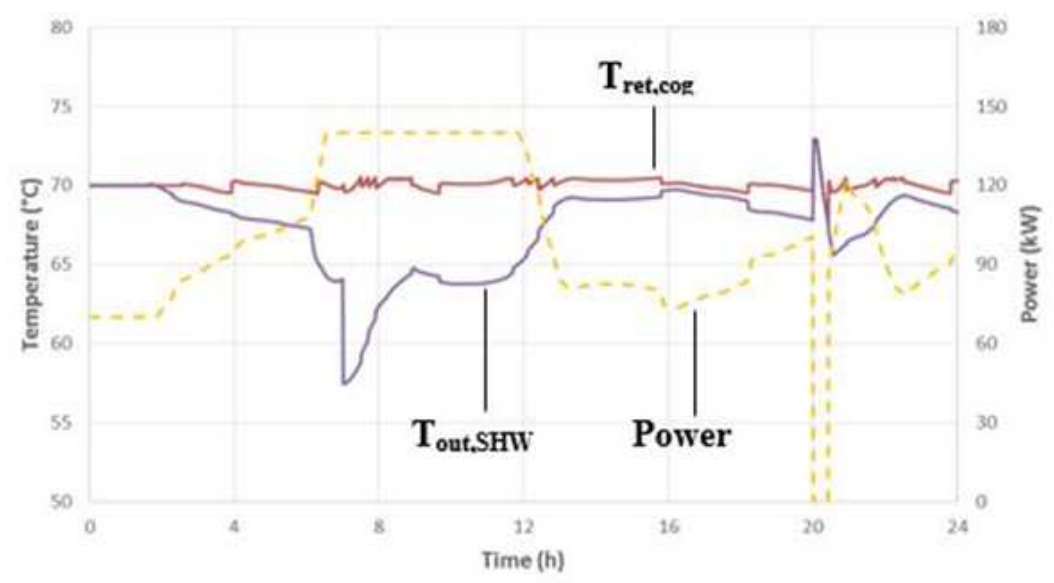

Fig. 7. Cogenerator controls

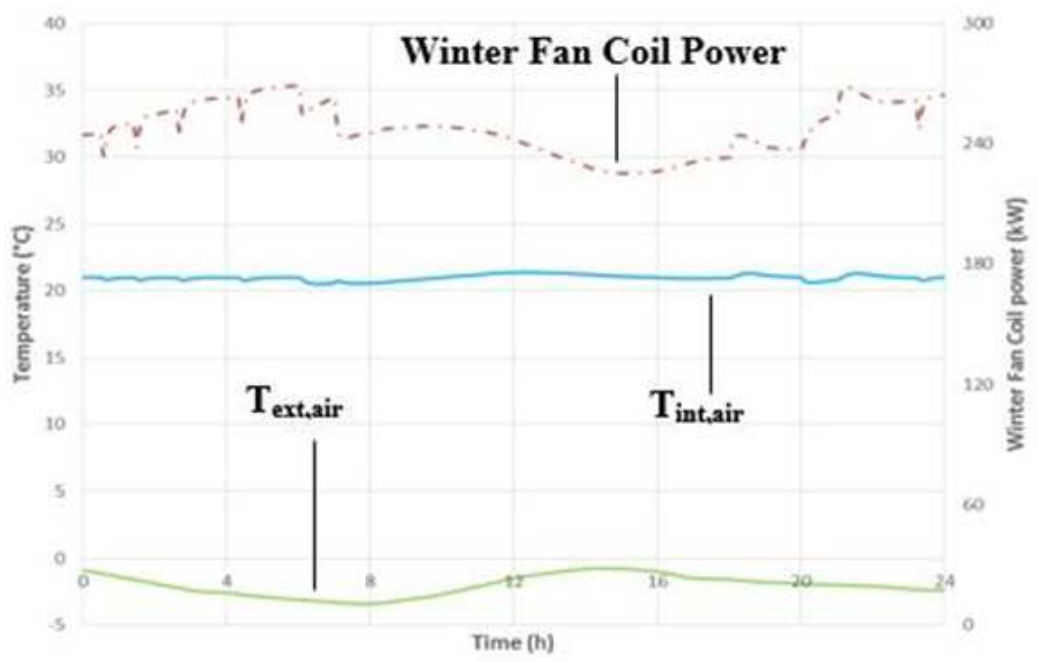

Fig. 8. Floors Zone indoor air temperature 


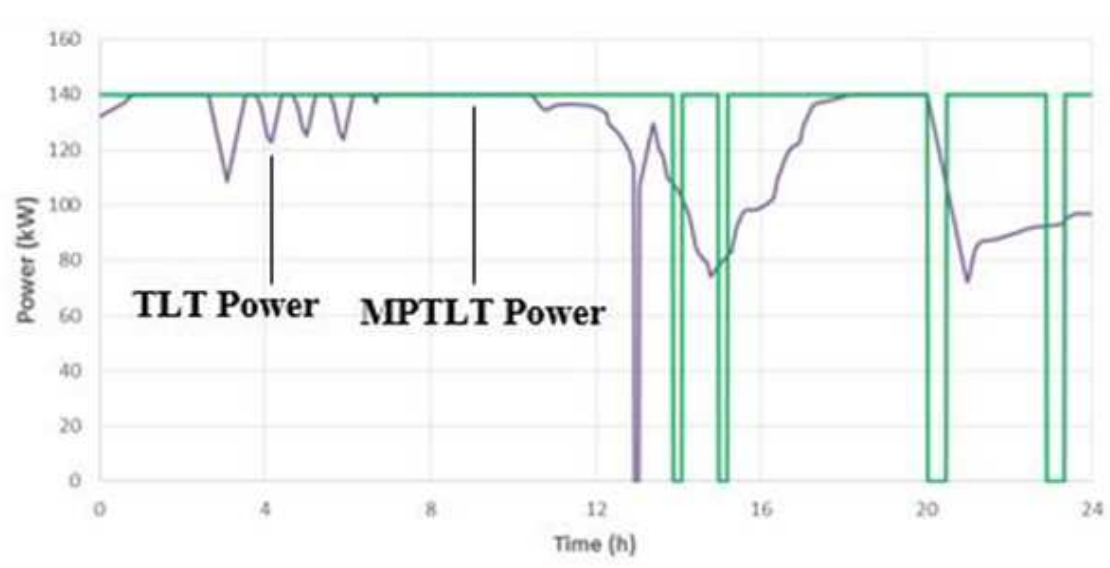

Fig. 9. Cogenerator off for TLT and MPTLT strategies

In the ELT, instead, because of the constant electrical load, the engine never stops working. Anyway, as already mentioned before, this strategy is possible only with the use of a suitable heatsink.

\section{Conclusion}

This paper presented an analysis of the operation of a Combined Heat, Cooling and Power (CHCP) system, by means of a dynamic simulation model, suitably developed to this aim in TRNSYS environment. An energetic analysis and an accurate economic model were developed, in order to evaluate the behavior of the engine and to improve the economic feasibility of the system. In addition to the typical TLT strategy used for hospital buildings, two different operating strategies were analyzed, obtaining a cost-optimal operating strategy as a function of the energy demands to be matched: Maximum Power Thermal Load Tracking (MPTLT); Electricity Load Tracking (ELT).

The main results can be resumed as follows:

- The trigeneration plant serving the hospital will provide energy, economic and environmental benefits

- $\quad$ The Typical Hospital Strategy (TLT) presents good values of the PES, but is the worst from the economical point of view

- $\quad$ SPB values for the TLT, MPTLT and ELT strategies are respectively: 4.4, 4.2 and 4 years

- PES values for the TLT, MPTLT and ELT strategies are respectively: 23, 24 and 14\%

- In spite of the heatsink, ELT strategy is the best solution from an energetic production point of view, providing $1203 \mathrm{MWh} /$ year of electric energy, $1794 \mathrm{MWh} /$ year of thermal energy and $184 \mathrm{MWh} /$ year of cooling energy

\section{Funding Information}

The authors have no support or funding to report.

\section{Author's Contributions}

All authors contributed equally to this work, they also revised and approved the manuscript.

\section{Ethics}

This article is original and contains unpublished material. The corresponding author confirms that all of the other authors have read and approved the manuscript and no ethical issues involved.

\section{References}

Aschaber, J., M. Hiller and R. Weber, 2009. TRNSYS17: New features of the multizone building model. Proceedings of the 11th International IBPSA Conference, Jul. 27-30, Glasgow, Scotland, pp: 1983-1988.

ASHRAE, 2001. Handbook of fundamentals. American Society of Heating, Refrigerating and AirConditioning Engineers, Atlanta.

Beihong, Z. and L. Weiding, 2006. An optimal sizing method for cogeneration plants. Energy Build., 38: 189-195. DOI: 10.1016/j.enbuild.2005.05.009

Calise, F., G. Ferruzzi and L. Vanoli, 2009. Parametric exergy analysis of a tubular Solid Oxide Fuel Cell (SOFC) stack through finite-volume model. Applied Energy, 86: 2401-2410. DOI: 10.1016/j.apenergy.2009.03.024

Calise, F., A. Palombo and L. Vanoli, 2012. A finitevolume model of a parabolic trough photovoltaic/thermal collector: Energetic and exergetic analyses. Energy, 46: 283-294.

DOI: $10.1016 /$ j.energy.2012.08.021 
Calise, F., 2016. Analysis of the optimal operation of trigeneration systems using dynamic simulations.

Chicco, G. and P. Mancarella, 2005. Planning aspects and performance indicators for small-scale trigeneration plants. Proceedings of the International Conference on Future Power Systems, Nov. 18-18, IEEE Xplore Press, Amsterdam, pp: 1-6.

DOI: 10.1109/FPS.2005.204203

Chicco, G. and P. Mancarella, 2006. From cogeneration to trigeneration: Profitable alternatives in a competitive market. IEEE Trans. Energy Convers, 21: 265-272. DOI: 10.1109/TEC.2005.858089

Espirito Santo, D.B., 2012. Energy and exergy efficiency of a building internal combustion engine trigeneration system under two different operational strategies. Energy Build., 53: 28-38. DOI: 10.1016/j.enbuild.2012.06.014

Kavvadias, K.C., A.P. Tosios and Z.B. Maroulis, 2010. Design of a combined heating, cooling and power system: Sizing, operation strategy selection and parametric analysis. Energy Convers. Manage., 51: 833-845.

Klein, S.A., 2006. TRNSYS: A transient system simulation program. Solar Energy Laboratory, University of Wisconsin, Madison.

Mago, P.J. and L.M. Chamra, 2009. Analysis and optimization of CCHP systems based on energy, economical and environmental considerations. Energy Build., 41: 1099-1106. DOI: 10.1016/j.enbuild.2009.05.014

Moussawi, H.A., M. Mahdi, F. Fardoun and H. Louahlia-Gualous, 2015. Recovery storage tank size: An optimization approach for tri-generation systems on diesel power generators. Energy Procedia, 74: 788-798.

DOI: $10.1016 /$ j.egypro.2015.07.814

Nayak, S. and R. Radermacher, 2004. Thermoeconomic simulation of $27 \mathrm{MW}$ campus Cooling Heating POWER (CHP) plant. Proceedings of the ASME International Mechanical Engineering Congress and Exposition, Nov. 13-19, Anaheim, California, USA, pp: 477-488. DOI: 10.1115/IMECE2004-60804

Piacentino, A., R. Gallea, F. Cardona, V. Lo Brano and G. Ciulla et al., 2015. Optimization of trigeneration systems by mathematical programming: Influence of plant scheme and boundary conditions. Energy Convers. Manage., 104: 100-114. DOI: 10.1016/j.enconman.2015.03.082

Sanaye, S., M.A. Meybodi and S. Shokrollahi, 2008. Selecting the prime movers and nominal powers in combined heat and power systems. Applied Thermal Eng., 28: 1177-1188.

Zheng, L. and E. Furimsky, 2003. ASPEN simulation of cogeneration plants. Energy Convers. Manage., 44: 1845-1851. DOI: 10.1016/S0196-8904(02)00190-5

\section{Nomenclature}

\begin{tabular}{|c|c|}
\hline$A C$ & After cooler \\
\hline ach & Absorption chiller \\
\hline$B B$ & Backup boiler \\
\hline$B C$ & Backup chiller \\
\hline$C$ & Cost $(€)$ \\
\hline$c_{E E}$ & Electric energy cost $(€ / \mathrm{kWh})$ \\
\hline $\mathrm{CHCP}$ & Combined heat, cooling and power \\
\hline CHP & Combined heat power \\
\hline $\mathrm{CHW}$ & Chilled water \\
\hline$c_{n g}$ & Natural gas cost $\left(€ / \mathrm{Sm}^{3}\right)$ \\
\hline$C O G$ & Cogenerator \\
\hline$C O P$ & Coefficient of performance \\
\hline$c_{p}$ & Constant pressure specific heat $(\mathrm{kJ} / \mathrm{kgK})$ \\
\hline$C T$ & Cooling tower \\
\hline$D$ & Diverter \\
\hline$E$ & Energy \\
\hline$E L T$ & Electrical load tracking \\
\hline ExJ & Exhaust gases-Jacket water exchanger \\
\hline$f$ & Dimensionless design factor \\
\hline$F$ & Fraction of thermal energy \\
\hline$F C$ & Fan coil \\
\hline$H E C$ & High efficiency cogeneration \\
\hline HEW & Heat exchanger winter \\
\hline$E S C$ & Energy Savings Certificates \\
\hline I & Component capital cost $(€)$ \\
\hline$J$ & Jacket \\
\hline$J W$ & Jacket water/heating Water exchanger \\
\hline$L C V$ & Natural gas lower calorific value $\left(\mathrm{kWh} / \mathrm{Sm}^{3}\right)$ \\
\hline$\dot{m}$ & Mass flow rate $(\mathrm{kg} / \mathrm{h})$ \\
\hline M & Mixer \\
\hline MPTLT & Maximum power thermal load tracking \\
\hline$N P V$ & Net present value \\
\hline$O C$ & Oil engine \\
\hline$P$ & Mechanical power $(\mathrm{kW})$ \\
\hline$P E$ & Primary energy ( $\mathrm{kWh} /$ year $)$ \\
\hline$P E S$ & Primary energy saving \\
\hline$P I$ & Profit index \\
\hline$P L R$ & Partial load ratio \\
\hline$P n$ & Pump \\
\hline$Q$ & thermal power $(\mathrm{kW})$ \\
\hline$\dot{Q}$ & Heat flow $(\mathrm{kW})$ \\
\hline$S$ & Saving \\
\hline$S P B$ & Simple pay back (year) \\
\hline $\mathrm{SHW}$ & Sanitary hot water \\
\hline$T$ & Temperature $\left({ }^{\circ} \mathrm{C}\right)$ \\
\hline$T K C$ & Cold storage tank \\
\hline$T K H$ & Hot storage tank \\
\hline$T L T$ & Thermal load tracking \\
\hline$U$ & Trasmittance $\left(\mathrm{kW} / \mathrm{m}^{2} \mathrm{~K}\right)$ \\
\hline$V$ & Volume $\left(\mathrm{m}^{3}\right)$ \\
\hline$\Delta C$ & Operating costs savings ( $€ /$ year) \\
\hline$\Delta T$ & Temperature difference $\left({ }^{\circ} \mathrm{C}\right)$ \\
\hline$\eta$ & Efficiency \\
\hline
\end{tabular}


Francesco Calise et al. / American Journal of Engineering and Applied Sciences 2016, 9 (4): 854.867 DOI: 10.3844/ajeassp.2016.854.867

$\begin{array}{ll}\text { Subscripts } \\ \text { aux } & \text { Auxiliary } \\ c & \text { Cooling } \\ D L & \text { Design load } \\ \text { el } & \text { Electrical } \\ \text { exh } & \text { Exhaust } \\ \text { ext } & \text { External } \\ \text { glob } & \text { Global } \\ h & \text { Heat } \\ \text { in } & \text { Inlet }\end{array}$

$\begin{array}{ll}\text { int } & \text { Internal } \\ N & \text { Nominal } \\ N G & \text { Natural gas } \\ \text { out } & \text { Outlet } \\ \text { rated } & \text { At nominal conditions } \\ \text { req } & \text { Required } \\ R S & \text { Reference system } \\ \text { set } & \text { Set by the controller } \\ \text { th } & \text { Thermal } \\ \text { tot } & \text { Total } \\ \text { vol } & \text { Volume }\end{array}$

